\title{
Paperwork, compassion and temporal conflicts in British social work.
}

\author{
YUILL, C., MUELLER-HIRTH, N.
}

2019

(C) The Author(s) 2018. 


\title{
Paperwork, Compassion and Temporal Conflicts in British Social Work.
}

Keywords: Compassion, paperwork, social work, wellbeing, temporal conflicts

\begin{abstract}
While previous literature has examined time discourses in social work and demonstrated that social work is predicated on linear understandings of time, one area that has received little theoretical and empirical attention in the literature on time and social work is what effects various social work temporalities exert on the lifeworld of social workers and how they shape their working days. This paper draws on semi-structured interviews with British social workers and employs an abductive approach to data analysis. By analysing the participants' experiences of time and work, the article identifies two temporalities that exist in social work practice, paperwork time and compassionate time. Paperwork time is linear, instantaneous and accelerated, requiring social workers to juggle multiple competing demands and needs. Compassionate time is slower and more developmental and cyclical and requires slower engagement. The paper then discusses how social workers negotiated these contradictory temporalities and highlights the potentially negative effects of temporal conflicts on people’s health, well-being and on social work practice at large.
\end{abstract}




\section{Introduction}

The temporalities of social work have come under increasing scrutiny. This interest stems from an implicit dimension of time that exists within social work practice. Social work, as both Parton (2008) and Philip (1979) note, is predicted on an essentially Kantian imperative that people can become more than they currently are, that their lives hold the possibility of being improved and transformed. The presence of becoming as an integral element of social work indicates a temporal configuration. Drawing from Ricoeur (1990), the present situation of a service user being in contact with social work services emerges out of - and is currently structured by - whatever individual and social malady affected them in their past. The basis of the present relationship between social worker and service user is therefore posited on negating the problems of the past by working towards a better future where the subjectivity and lifeworld of a service user is healed, reformed or transformed. This temporal direction is why Fahlgren (2009) refers to social work as 'future work': a better and more desirable present for someone existing in the future that overcomes the distress of the past and the present. All of the interactions between social worker and service user are therefore configured on the realisation of this desired future by working towards that endpoint. This time orientation involves an understanding of time that is linear and progressive, envisioning a binary transition, for service users, from being damaged and incomplete to becoming repaired and complete functioning members of society. However, what we might think of as a therapeutic production line might entail negative consequences for service users, since lived experiences of time (as is the case for all of us) run to more fluid and less predictable sometimes chaotic - rhythms. Yet, these rhythms can be cast as deviant and problematic (Juhila et al 2015). This rendering of particular temporalities as deviant or indeed inferior highlights a related issue: while there are potentially multiple temporalities, these are not equal. There are conflicts and power differentials in the uses and understandings of time. Critical time studies demonstrate that control over time is a medium of hierarchical power and governance and time plays an important role in social methods of inclusion and exclusion (see for example Bastian 2014, Bryson 2007, Halberstam 2005, Auyero 2012).

While social work has been demonstrated to be predicated on linear understandings of time (Fahlgren 2009, Roberts 2017), one of the areas that has received insufficient theoretical and empirical attention in the literature on social work temporalities is what effect the various 
temporalities, linear or otherwise, that are at play in social work exert on the lives of social workers. Previous work does touch on this issue. Fahlgren (2009), drawing on the work of Barbara Adam, describes the discourse of the mindful body, which she characterises as social workers' subjective understandings of people's past, present and future that contrast with the future-oriented linear discourse of time. Statham et al (2006) similarly write about 'therapeutic rhythms'. These are useful speculative comments on social work temporalities, but they require further empirical work to capture and analyse social workers' experiences of attempting to be mindful or therapeutic in their work and to understand their subjective experiences of negotiating complex and contradictory temporalities. There have also been a number of time-use studies of social work (for example, Cleaver et al. 2004). Whilst they make a valuable contribution in summating the time social workers devote to specific tasks, they lack, as Statham et al (2006: 4) critique, an appreciation of the social workers 'subjective impressions and understandings' of how they spend their work time, which cannot be measured instrumentally in minutes, hours and days.

Drawing on semi-structured qualitative interviews with 16 social workers employed in the British public sector, this article brings to the fore the temporal experiences of these social workers. Doing so attends to the gap in the literature discussed above by establishing empirical insights into how social workers negotiate and interpret the demands of often competing and contradictory temporalities. The empirical data in turn allows for developing and refining theoretical perspectives on social work temporalities and identify the tensions and conflicts that can exist between these different temporalities. The main findings centre on (1) the existence of an emotionally powerful 'compassionate temporality', (2) which is frequently marginalised by the presence of contradictory and chaotic 'paperwork time', and (3) the negative impacts that marginalisation has on participants' health and wellbeing as they spend their time juggling a these conflicting temporalities.

The article unfolds in three parts. A commentary on study design opens the main body and outlines the use of semi-structured interviews and of abduction in the analysis of data. As a mode of inference, abduction allows for greater iteration between data, existing literature and theory than found in the conventional use of grounded theory. Attention then turns to review the relevant literature on temporalities and social work. Two issues are particularly highlighted here: the dominance of a specific form of linear time and how that is hegemonic over other, more complex 
and rhizomorphic, temporalities; and the impact of new public management and broadly neoliberal ways of organising on the temporal orders of social work in Britain. We then turn to the analysis of the interview data. Participants' narratives highlighted a dominant linear temporality that was expressed in what we term 'paperwork time': a temporal instantiation of neoliberal management and disciplinary technologies that shapes social workers' lived experiences in and out of work through a contradiction of deceleration and acceleration. Paperwork time contrasted with a desired 'compassionate temporality', where time is devoted to working to the rhythms of the needs of service users and practicing the craft and skills of social work. There emerged, we argue, conflicts between these temporalities for the social workers we interviewed, which impacted on many of the participants' health and wellbeing.

\section{Study design}

Drawing on contacts in local trade union networks approaches were made to social workers in a variety of locations within a British city and surrounding region. Recruitment proved to be more challenging than anticipated. While many prospective participants indicated that they wished to be part of the research it was hard to translate this interest into actual interviews. The main reason that many gave when they declined, and this will be reflected on in the discussion, was that whilst they were interested they did not have spare time to take part. The group of participants that were interviewed did, however, include a range of social workers of different lengths of service and experiences of working within a variety of social work sectors.

With a qualitative approach relatively small numbers can yield rich data. As Marshall (1996) and Guest, Brunce and Johnson (2006) note, data saturation can be reached after 12 interviews. That was the case here, though it was decided to proceed with further interviews to ensure that no new data would emerge, hence the final number of sixteen participants (their biographical details can be found in figure 1 below). The questions for the semi-structured interview schedule were generated from previous research experiences and from the literature. They sought to elicit experiences of working, reasons why the profession was chosen, and issues of health and wellbeing. As with any semi-structured interview flexibility was integral to the interviews with a series of mining and follow questions being used to gather richer layers of data. The interviews were transcribed and then subject to an iterative process of coding. The initial research was focused 
on workplace health and wellbeing. It was not until after the interviews had been transcribed and analysed that it became apparent that time was a critical issue for the social workers. This finding was truly grounded in the data and had not been anticipated in advance.

Once the centrality of time had been identified, a second analysis of the transcripts was undertaken, this time with an emphasis on the temporal aspects of participants' experiences and understandings. Time and related issues saturated the participants' accounts of their working (and non-working) day. Codes such as ‘juggling time’, ‘crash point', 'busy', ‘time scarce’, 'past lifehistory', 'compassionate time', 'a better past', and 'paperwork time' emerged during the analysis, alongside more instrumental codes that reflected the frequency of the mention of time or units of time.

An abductive inferential approach was adopted in analysing the data because of its advantages in relation to theory development over the traditional choice of grounded theory common in qualitative research. As Yuill (2017) and Timmermans and Tavoy (2012) have argued, abduction allows for the expansion of existing theory and research by engaging in a dynamic and iterative interplay of data, theory, literature and novel insight, a move that is barred in the purer forms of grounded theory. ${ }^{\mathrm{i}}$ It also licenses a more creative approach to analysis than found with inferential or deductive modes of analysis, both of which limit the originality of what can be discovered (Danermark et al, 2002).

Figure One: Participants’ biographical details and work histories.

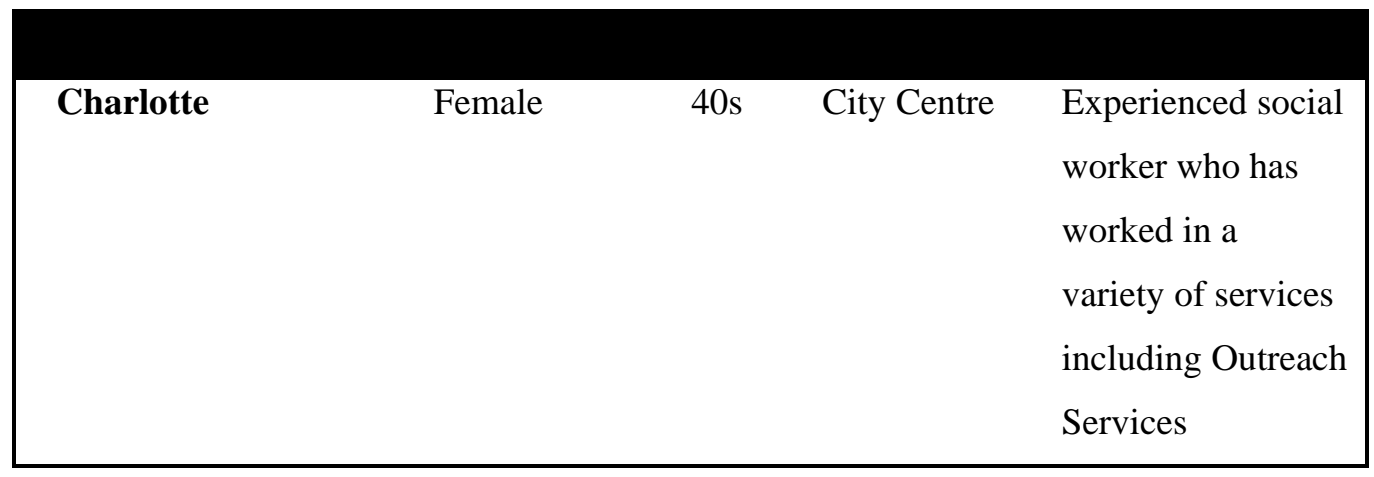




\begin{tabular}{|c|c|c|c|c|}
\hline Richard & Male & $50 \mathrm{~s}$ & City Centre & $\begin{array}{l}\text { Came to social work } \\
\text { later in life mainly } \\
\text { due to his socialist } \\
\text { beliefs }\end{array}$ \\
\hline Joe & Male & $20 \mathrm{~s}$ & City Centre & $\begin{array}{l}\text { Not long in practice, } \\
\text { graduating a year } \\
\text { before the interview }\end{array}$ \\
\hline Sarah & Female & $40 \mathrm{~s}$ & City Centre & $\begin{array}{l}\text { Came to social work } \\
\text { later in life to find a } \\
\text { more fulfilling life }\end{array}$ \\
\hline Kate & Female & $20 \mathrm{~s}$ & City Centre & Newly qualified \\
\hline Rebecca & Female & $20 \mathrm{~s}$ & City Centre & Newly qualified \\
\hline Lee & Male & $30 \mathrm{~s}$ & $\begin{array}{l}\text { South City } \\
\text { Services }\end{array}$ & $\begin{array}{l}\text { Came to social work } \\
\text { later in life and has } \\
\text { circa six years } \\
\text { experience. }\end{array}$ \\
\hline Craig & Male & $20 \mathrm{~s}$ & Beachside & $\begin{array}{l}\text { Has been working in } \\
\text { social work for over } \\
\text { five years in a } \\
\text { variety of services }\end{array}$ \\
\hline Bob & Male & $50 \mathrm{~s}$ & Beachside & $\begin{array}{l}\text { Long-serving social } \\
\text { worker with nearly } \\
\text { thirty years } \\
\text { experience }\end{array}$ \\
\hline Nathan & Male & $40 \mathrm{~s}$ & $\begin{array}{l}\text { East Central } \\
\text { Services }\end{array}$ & $\begin{array}{l}\text { Long-serving social } \\
\text { worker who has } \\
\text { worked in a variety } \\
\text { of locations }\end{array}$ \\
\hline Jennifer & Female & $20 \mathrm{~s}$ & Farside & Recently qualified \\
\hline Rachel & Female & $20 \mathrm{~s}$ & Farside & Recently qualified \\
\hline Frances & Female & $50 \mathrm{~s}$ & $\begin{array}{l}\text { Outreach } \\
\text { Services }\end{array}$ & $\begin{array}{l}\text { Long-serving social } \\
\text { worker, who has }\end{array}$ \\
\hline
\end{tabular}




\begin{tabular}{|c|c|c|c|c|}
\hline & & & & $\begin{array}{l}\text { worked in a variety } \\
\text { of locations }\end{array}$ \\
\hline Peter & Male & $40 \mathrm{~s}$ & $\begin{array}{l}\text { Outreach } \\
\text { Services }\end{array}$ & $\begin{array}{l}\text { Came to social work } \\
\text { later in life and has } \\
\text { been in practice for } \\
\text { a few years. }\end{array}$ \\
\hline Sheila & Female & $50 \mathrm{~s}$ & East city & $\begin{array}{l}\text { Came into social } \\
\text { work later in life but } \\
\text { has been a basic } \\
\text { grade for over ten } \\
\text { years. }\end{array}$ \\
\hline Fiona & Female & $50 \mathrm{~s}$ & West city & $\begin{array}{l}\text { A long-serving } \\
\text { social worker with } \\
\text { thirty year's } \\
\text { experience in both } \\
\text { the voluntary and } \\
\text { statutory sectors. }\end{array}$ \\
\hline
\end{tabular}

\section{Social work and temporalities}

The existing literature on social work and time has been predominantly concerned with the time orientation of the field as ‘future work' (Fahlgren 2009, also see Juhila et al. 2015). Juhila et al.'s (2015) analysis of social work interactions, for example, indicate that many conversations between social workers and users were structured according to a timeline in which the service users are expected to progressively and continually improve and social workers kept referring to the future, while service users were often far more concerned about the immediate present. The dominant linear timeframe assumes steady progression through discrete stages, each of which realise an incremental change in the lifeworld of the service user. This linear nature of social work reflects Enlightenment ideas of progress and planning (Fahlgren 2009), but eschews the irrationality of subjects' lives and the complexities of precarious and chaotic lives conditioned by long-term and demanding care needs. Other scholars share this scepticism that social work can be distilled to a singular temporality, pointing to the problems that a linear temporality implies within social work 
practice (Juhila et al. 2015, Pösö and Eronen 2015). By exploring how discourses of time are produced and negotiated in professional client interaction, Juhila et al. (2015) identify that the hegemonic nature of linear time creates a disciplinary mechanism of compliance that judges other temporal pathways as deviant, inferior or indicative of failure.

The observation that service users, and indeed social workers, experience time in ways other than linear, is consistent with the existing literature in other fields that posits lived times as non-linear and non-chronological, as set out before. The existence of such alternative temporalities in social work has been explored by Pösö and Eronen (2015). According to the authors, three other temporalities emerged in addition to dominant linear time: fragmentary time, curricular time and silent time. In a study of Finnish welfare service workers, Hirvonen and Husso (2012: 355) analyse temporal variations in workers' agency and note the 'parallel temporal frames' - economicrationalistic and relational - in welfare services.

One of the aims of this article is to set out in what ways different temporalities might be in tension or conflict and how such temporal conflicts affect social workers. Juhila et al.'s research -briefly mentioned above - demonstrates that 'clashing time talk' occurs when 'the client does not promise to commit to the regular (task-oriented) week programme forming a linear progressive continuum, but states that he needs to live his life more according to his here and now emotional state (2015: 18). Their focus is on clashes between professionals' and clients' uses of discourses of time, however, while we are concerned with social workers' experience of time and of temporal conflicts. Davies (1994) similarly studied, through ethnographic work, the tensions between different time discourses in care work in Swedish day nurseries, distinguishing primarily between non-linear process time and task-oriented clock time. It might be argued that temporal conflicts characterise work 'with people', such as education, healthcare, social work and youth work, more generally (Ylijoki and Mäntylä 2003), precisely since these fields are dominated by process- or 'concrete time' (Colley et al. 2012). The adoption of neoliberal policies in welfare provision has only intensified the tensions between different time orders in these fields of work; for example, Colley et al. (2012: 385) argue that the pressures of 'abstract time' over 'concrete time' in youth support work in England led to practitioners' increased stress levels or leaving the profession; for academics, tensions between 'scheduled time' and 'timeless time' can impact on the quality of 
research and a sense of self-fulfilment (Ylijoki and Mäntylä 2003). Davies (1994: 287), in relation to Swedish care work, argued that staff reductions on the back of funding cuts 'forces a clock-time relationship on what needs to be carried out in a process-time manner.' Our article contributes to this adjacent literature by examining the temporal experiences of social workers in Britain, developing the notions of paperwork time and compassionate time from empirical data, and tracing the temporal conflicts that might arise from these multiple temporalities.

The picture of British social work we develop in our discussion below has, as three of the older participants noted, not always been like it is today. In the 1970s temporalities of practicing social work were radically different. Harris (1998) describes that period as being one of 'parochial professionalism'. Social workers exhibited much greater freedom over how they interacted with service users, how they structured their time and how they related to each other. Time was focussed on the craft of social work, the use of various in-depth therapeutic techniques they had acquired during their training, in transforming the lives of the people with whom they worked. Notably absent was paperwork as an activity. If an interaction with a service user (or client, in the language of the time) was documented then it was as an aide memoire for the social worker. There was no formal requirement to keep extensive records.

A fundamental transformation of social work and its temporalities begins in the 1980s. A variety of neoliberal projects introduced by the various Conservative governments from the 1980s onwards and by (New) Labour administrations in the 1990s resulted in reordering social work into what Harris (1998) terms the 'social work business', increasingly beset by the introduction of market disciplines. The linear future work that Fahlgren has identified as being a core temporality for social work consequently becomes increasingly colonised and controlled by the governmental techniques of neoliberal managerialism. Lymbery (2001: 370) argues these transformations resulted in the loss of the social work 'mission': the idea that social work is not just another type of job but, rather, a means by which to create a better society and to positively work with vulnerable, minority and marginalized groups in society. Time and service user progress become measurable and auditable so as to (supposedly) increase efficiency and move service users through a social work service in as quick a time as possible. As Dardot and Laval (2013: 250, emphasis added) state, the impulse within neoliberal management to evaluate, measure and audit assserts 
greater managerial control whilst reducing worker autonomy, but also goes much deeper in attempting to transform what it is to be a professional within the public sector:

Measuring performance has become the elementary technology of power relations in public services... It tends to shape the activity itself and aims to produce subjective changes in the 'evaluated', so they meet their 'contractual commitments' to higher bodies. This involves reducing the autonomy acquired by a number of professional groups, such as doctors, judges and teachers, who are deemed to be expensive, lax or unproductive, by imposing on them the criterion of results constructed by a proliferating expert technostructure.

The looser and fluid temporalities of parochial professionalism gave way to a highly structured and intense temporality, one governed by the requirement to monitor and record multiple aspects of the progress of a service user. As Munro (2004: 1093) notes social work became '... directed at paperwork attached to the work, not at the intricacies of their actual work with people.' Critical to enabling this new temporal mode was the 'electronic turn' within social work, where the social work office increasingly resembles any other office spatialised by computer technology (Garret 2005). Whether or not ICT improves social work practice is far from clear, as Chan (2016) has argued. Without doubt though, this temporal shift has 'resulted both culturally and organizationally in greatly intensified demands for instantaneous responses and failsafe social work, especially in child protection’ (Ferguson 2008: 575) ${ }^{\text {ii }}$.

The time conflicts that we discuss when we analyse the interview data next are not at root the outcome of a simple lack of resources or a case of the individual social worker being overwhelmed by case work; rather they are the outcome of neoliberal governmentalities and the radical reorganisation of British social work that has unfolded since the 1980s. Neither of these have been fully analysed from the standpoint of time and temporalities.

\section{The contradictions and tensions of paperwork}

Asked to describe a typical working day, one time-intensive activity, above all others, appeared constantly in the interviews: the requirement to complete statutory audits and case reports (or 
'paperwork', to use the participants' expression). Kate provides a succinct summary of participants' perceptions of paperwork:

The nature of the beast is paperwork, paperwork, there's sort of big pressure that all those things have to be done. We're maybe coming from, let's help people kind of a view, it's maybe not your key focus to do the paperwork things (emphasis added).

The hegemonic presence of 'paperwork time' (more of which soon) was discussed by all interviewees. Charlotte, an experienced and long-serving social worker, commented that, when she worked in Outreach Services, completing paperwork took 'priority over everything else, really', and that, 'a lot of time in Outreach Services is taken up with report writing'.

Richard focused on how much of his time is absorbed in either the completion of paperwork or attending meetings:

Paperwork and stuff? It's disproportionate! I was trying to work it out the other day. [...] With the adult protection thing, it's increased a bit. Probably of the five days a week, [...] there is some assessment clinics like meetings to go to. Probably only two days a week [out of five] I'm seeing folk.

The telling aspect of Richard's account is how little time he spends with service users. Richard's perception of paperwork taking up the bulk of the working week was reiterated in other participants' accounts. Estimates varied across the participants to between $40 \%$ to $60 \%$ of their time at work (with most reporting towards the upper end) being absorbed by paperwork. ${ }^{\text {iii }}$ Time use studies in social work indicate that the social workers in this study were not exceptional in their frustrations about paperwork 'taking over': pressures and performance indicators have reduced contact time and weakened relationships between social workers and families (Dominelli 2009, Munro 2011). ${ }^{\text {iv }}$

The term 'paperwork' here does not refer to physical entities of actual paper. It is the symbolic shorthand participants developed to describe a variety of digitised case notes, reports and statutory 
documents that they are required to complete in order to monitor and assess a service user's progress $^{\mathrm{v}}$. Reports can be between circa 12 to circa 20 pages long, depending on the particular branch of social work or geographic region. The structure of a report is a pre-determined template populated with various domains and Likert-scale metrics to measure some attribute of the progress that a service user is hopefully making. Any narrative account or personal commentary on a case that a social worker may have is minimal and constrained to answering specific points within a limited word count.

The fundamental essence of paperwork is to measure and monitor the progress of a service user, critically mapping out their forward trajectory to a point in time where the issue that was negatively affecting their life is positively transformed. In addition to structuring the time of the service user, paperwork acts as a disciplining technology also structuring the time of the social worker. Since the paperwork is statutory it has to be completed in a prescribed form and within a set time-frame.

Participants reported that, in some offices, a distinct informal culture had emerged based on the accelerated demands of contemporary social work $^{\mathrm{vi}}$. Colleagues expected their peers to be constantly working and to be stressed and overwhelmed with their workloads, as was usually the case. If they were not, it was interpreted as not working hard enough, not having enough to do or somehow offloading work onto others. Taking any form of break or not performing at a hectic pace of work was open to informal sanction, such as shunning or ignoring the apparently deviant. One participant, Peter, commented on this culture of constantly being seen to work when he described lunchtimes and how no one appeared to actually take the time off for lunch to which they were entitled:

It's a culture that's developed where people go out to the shops to get their lunch and they'll come back. But nobody will spend a solid hour out of the office, very rarely for a long period of time just to get away and it is a culture that has developed over time.

The temporality of paperwork discussed here reflects the lived experiences of participants' time. Paperwork time produces the inverse for the social worker, whose working day is narrowed to a hectic - if not chaotic - instantaneous present of multiple and competing demands and tasks. Its 
rigid linear direction is embedded in the physical and material form of (digital) paperwork that disciplines both the service user and social worker into that temporal frame. Paperwork time is also a contradictory temporal mode, simultaneously exhorting speed but slow to complete.

The contradiction of paperwork time, being simultaneously both linear but yet chaotic, is exemplified by recently qualified Rebecca. She reflected that she liked to have a structured and ordered day where she could measure her progress by ticking off deadlines that she had reached and by completing her to-do-lists. Her structured linear approach should easily match the linear direction of Fahlgren's (2009) future work. That way of working was not possible, however. Having to work with a caseload of up to forty-five participants required switching between cases and made it difficult for her to feel that any one task was ever properly completed. As she said: 'My to-do-list? I didn't even have time to do a to-do-list!' The time scarcity she experienced and the amount of tasks she needed to undertake in that time resulted in her feeling frustrated with work and sometimes it led to her feeling 'stressed to the hilt'.

She was working through multiple insidious demands and her attention was spread to simultaneous multiple foci, all of which required a response in a narrow time frame. Her experiences were shared by all other participants who also described their working days as dense with multiple concurrent demands. When asked to describe a typical working day, Nathan offered the metaphor of being a juggler and having to simultaneously balance many different competing demands that emerged from the need of co-workers, managers and service users. Their needs and requests frequently required immediate attention and interrupted other tasks, resulting in a rushed, hurried and almost chaotic working experience. Nathan referenced a sketch from the popular British family television show The Generation Game to convey his sense of juggling at work. This vignette captures the lived experience of coping with instantaneous time that many of the other participants also expressed:

You're constantly chopping and changing. You're shifting from one person to another person. You are interrupted by a phone call. You've to finish something for a deadline. You're constantly juggling different demands from different people, whether it's your service-users, your management or your colleagues or the people you are working joint 
with, other professional people. It's like being a juggler and that's the phrase I'd use. It's juggling. You are probably not old enough to remember the Generation Game. You'd used to occasionally get a guy who'd come on with sticks and he'd put plates on the sticks and he'd start. He'd get them going and the plates would twirl independently on top of these sticks. But ultimately you'd get to the point where you'd be asked to twirl so many sticks that some of the plates start to fall off - you can't keep them all going at once.

From the participants' accounts of the workplace it was clear that what we have termed paperwork time was the dominant temporality within their workplaces. As discussed in the previous section what the participants refer to as 'paperwork' is a technology of neoliberal governance that seeks to alter social work and what it is to be a social work. The participants accounts of their working day were replete with references to paperwork time, not as an expected part of the job, albeit a tedious one, but as an alienating temporality that they perceived as intruding into what they thought social work should be its purpose and how they should, as social workers, spend their time. How they as social workers though their time should be structured is analysed in the next section.

\section{Compassionate temporality}

The interviews also revealed another temporality that existed for the participants. Reflecting on why they had chosen to become social workers, participants indicated their decision was based on a fundamental aspect of self that they termed the 'compassionate self'. This aspect of their identity spoke to a desire to do good by others in their working lives. They emphasised their work was not based on instrumental or financial grounds but on realising and externalising a deep facet of their subjectivity.

For some, their compassionate self was formed early in life, often as a result of recognising the suffering of others, as Jennifer and Rachel highlight:

I think that it was experiences that I had had when I was younger. I had seen a lot of people in need and there wasn't any response to that and I felt that I wanted to be with that person. To fill in that contradiction. 
Yeah, all through school I wanted to do a job meeting people and working with people and helping people. My mum was very much focused on that area as well. I didn't want to be stuck in front of a computer all the time, superficial contact, the more in- depth not working in that kind of area you know, but in-depth touch with people.

For others, the compassionate self emerged out of a disenchantment with the substance of their previous employment. They sought work that provided greater meaning and purpose by working to better the lives of others. The compassionate self gives rise to what we call a 'compassionate temporality', where the rhythms of the working day are devoted to working with and helping other people. For social workers generally, and for the participants in this study, the compassionate temporality entails using the various skills, counselling and therapeutic techniques (for example, talking therapies) they learned during their studies at university, and spending time working intensively with service users. The enactment of such skills possesses different and complex temporalities. They are often slow and require time to be effective. Progress cannot always be incrementally measured, or it does not develop in a linear manner and co-exists with times of stagnation and repetition. To that extent, the compassionate temporality shares the telic direction of the Fahlgren's future work and the Kantian notion of improvement outlined at the top of this article. It also shares common ground with Fahlgren's reworking of Adam's (1990) ‘time of mindful body'. However, it does not merely describe social workers' interaction with service users, but also speaks to their own being in the world. The journey from the present to the future is rhizimorphous, embracing different fluid temporalities that respect the needs and circumstances of both service users and social workers.

The compassionate temporality was desired by the participants but became subordinated and marginalised by paperwork time and rendered as a fleeting and occasional experience. This observation is perhaps unsurprising, given the privileging of speed over slower times in the temporal order (Sharma 2014, Adam 2004). All of the participants could identify nonetheless moments in their career when a compassionate temporality had existed for them. Richard, an older and experienced social worker, reflects on an earlier job within social work where he had greater 
autonomy and control in structuring the job. He was, as a result, happy to work at weekends and let the work spill into other temporal spheres of his life:

I know it was a much smaller job I was covering the whole of [area anonymised]. A lot of driving about, you know, and extra work to do for my boss to do with the running of the service on top of my caseload. It had its own pressures as well but just, you know, again you didn't feel, but because it was mine. Because I created it and it was my baby. To a certain extent I had a lot more ownership with it. And I felt I could go in on a Saturday and work all day on a Saturday and not bat an eyelid about it.

Participants framed those exceptional moments when they could enter the flow of a compassionate temporality as times that made the job worthwhile and as such partially compensated-for the pressures of paperwork time. It could be argued though that this partial compensation contributed to the reproduction of paperwork time and accounts for why participants continued in the profession despite how demoralising and damaging it could be for them. Participants were willing to endure continual and extensive periods of alienating experiences for brief moments of selfrealisation.

\section{Embodied experiences of multiple social work temporalities}

All of the above - the frantic workloads and the temporal mismatch between expectations and reality, between paperwork time and compassionate time - impacted on the wider lifeworld of the social workers. The effects varied across the participants, but two types of responses were most common. The first response was disillusionment with social work as a career. Peter voiced his disenchantment as follows:

I thought it was going to be more about contact with clients, you know, motivating change in people's lives rather than being on a desk writing out reports that are due in a certain timeframe.

This sentiment of disappointment was expressed by other participants too. Frances, who had been a social worker since the 1980s, evinced a deep disillusionment - if not despair - at being a social worker: 'I find it stressful and demanding and exhausting. I came in with a real positive outlook 
but now it is very negative.'

On a more insidious level participants felt that the temporalities of work structured and conditioned their being in time beyond work, in the private spheres of their lives. On Friday nights, after work, many reported experiencing a sense of 'dread' and anxiety that they had missed something, that a service user may come to harm or that they had not completed some necessary bureaucratic requirement to ensure that support for a service would be in place. The sense of dread returned on Sunday, this time in anticipation of what issues and challenges awaited them on Monday morning, as Rachel captures below: 'It was really bad. It was quite constant. Only for a few hours on Saturday I wouldn't think about work [...] Sunday came and the dread came and it came to the point thinking about work, speaking about work the whole time.'

The second response related to health and wellbeing. The longer serving social workers noted that trying to balance all the demands being made upon them became unsustainable over time. Nathan, who had been a social worker for over 20 years, termed this a 'crash point', where the incessant competing and multiple demands on his time became too much: the juggler he referred to above was unable to keep all the plates spinning at once, and the whole came crashing down. An extended period unwell and off work often followed.

The crash point is a critical moment that is short and sharp in its onset, but with longer term consequences. Many of the longer served social workers had experienced such a crash point. It was initiated by what may have been a seemingly small or commonplace aspect of daily work (for example, filling in a form or visiting a service user), which however refracted all the tensions inhered in balancing paperwork time with the desired compassionate temporality. The crash point is then perhaps the clearest embodied manifestation of the temporal conflicts for these participants. It crystallises all the issues with which they had been dealing leading to a collapse in health and wellbeing. Sheila reflects here on her crash point moment: 'When it came to going to my client after that I just couldn't face it. I broke down in tears and told my colleague I needed to go home. So we returned to the office and I went home. I was then off after that. So that had been my actual breaking point.' Her crash point resulted in several months of work with stress and depression. Charlotte, also an experienced social worker, remembered a time when her health and wellbeing 
were negatively impacted by trying to meet the demands of work and reaching a crash point of her own:

I was very unwell. I didn't realise until I left that job. [...] I was off work for about six weeks: signed off by my GP. I developed a chest infection. I smoked more and drank more alcohol as a way of managing the stress I was under. I was off for six weeks, at one point with a chest infection that was the result of poor living and working as many hours and stressed out all the time

Bob, the longest serving social workers of the interviewees, was actively seeking early retirement as he was concerned that his health would be seriously impaired if he remained in social work. Though the crash points were mainly experienced by longer serving social workers, Lee recalled a time supervising a young student on a placement whose compassionate self was a strong element of her identity. The reality of social work, extant in paperwork time, overwhelmed her and she left the placement early due to stress.

For some participants experiencing a crash point led to a period of existential contemplation on what was important in life and what should be given priority in both their working and private lives. They reflected on how they interpreted their time and what to do with it. Nathan, for example, noted how his crash point resulted in him adopting a 'different perspective' on his working life. This decision entailed investing less emotional importance in the role of work and giving more time to activities beyond work. Richard's moment of crisis led him to reorient his energies and more of his time on his wife who had also recently suffered poor health: 'now when you've events happen in your life, you've got to refocus on what's more important: a job in the end is just a job.' On the whole, however, the impact of multiple and potentially conflicting temporalities on social workers' health and wellbeing, and on their understandings of their profession, was negative.

\section{Conclusions}

This paper has identified, through empirical research, new social work temporalities that can be added to the range of time discourses identified in previous, largely conceptual, literature. In particular, the paper has explored some of the effects of these social work temporalities on the 
lives of British social workers in this study, rather than focusing on service users or on the temporal conflicts between social workers' and service users' experiences of time. Compassionate time emerged in the accounts of the participants as a desired temporality. This mode involves healing the damaged lives of others and ameliorating their suffering. It is structured by the needs of service users congruent with the unpredictable rhythms of their lives and by the skills and knowledge of the social worker. It eschews temporal hierarchies or the stigmatising of rhythms that may seem disorganised or chaotic, but recognises that multiple forms of time are required in social work.

Compassionate time may seem to be the obvious temporal mode that should exist in social work, given the profession's focus on working with people who are leading damaged or problematic lives. In the daily working experiences of the participants however, compassionate time was fleeting and contingent; a desired-for temporality that was seldom realised and, consequently, selfrealisation was rarely attained. Instead, what we have called paperwork time shaped participants' everyday experiences of work time and their experiences of life outside of work. Rather than merely involving a linear logic and progressive directionality, as has been described in relation to social work practice elsewhere (Fahlgren 2009), this temporal mode of paperwork time reflects the structural changes that social work has undergone in the neoliberal era and its culture of speed, creating a work place dense with multiple demands, particular temporal expectations and short time frames. This, in turn, was demonstrated to lead to potentially damaging working environments, deleterious health and well-being and social workers' senses of being overwhelmed by having to juggle competing demands in ever-shrinking time frames.

There are, therefore, temporal conflicts that characterise social work practice as experienced by the social workers interviewed for this study. The. main conflict that shapes social workers' engagement with their profession, with service users and colleagues is, we argue, between paperwork time and compassionate time. As our data demonstrates, trying to reconcile these two temporalities was a difficult task. On one level, the constant demands lead to feelings of stress but it also affected the participants on deeper levels too. Many of the respondents felt that they had reached a 'crash point': a moment when the contradictions between their own desires for what they wanted social work to be and the reality of their work proved to be too much. Their experiences 


\section{of spending too much time on paperwork but not enough on working with people also corroded} their sense of self.

\footnotetext{
i A full and thorough explanation of abduction can be found in Yuill (2017).
}

ii The analysis in this paper focuses on temporalities in British social work, which emerge out of particular political, economic, cultural and historically contingent processes and influences. We therefore make no claims as to how social work temporalities have been shaped and conditioned in other national territories given that different conditions will have been in operation. In Germany, for example, Colley et al (2012) identify that time dedicated to social work processes is priviledged over other temporalities.

iii It should be noted that social work has not always operated to this temporality. Providing a history of how social work temporalities have changed is an article in itself. Briefly, however, the various reforms associated with the neoliberal project in Britain radically transformed the easy going and loose temporality of what Harris terms 'parochial professionalism' that existed in the 1970s. Social work from the 1980 became increasingly colonised by private-sector practices that introduced surveillance, control and target driven outcomes. As a consequence of those developments social work temporalities became more structured and organised by influences external to the profession.

iv Earlier time use studies (Weinberg et al, 2003, cited in Statham 2006) highlighted the low percentage of time spent by care managers on face to face contact, concluding that 'what has changed over time is not the overall balance between types of work, but the nature of direct contact with the service user' (ibid: page xx); other work has shown the considerable amount of time it takes to conduct assessments (Cleaver et al., 2004, cited in Statham 2006). A survey, conducted in 2005, of two thousand social care professional found that 95\% agreed that social work had become more bureaucratic and less client-focused over the past five years, due to the need to compile performance data and increased reporting requirements (Samuel 2005, cited in Statham 2006). While this survey was not representative and did not exclusively focus on social workers, it highlights the pressures that were felt around bureaucratization and what we call paperwork here already over a decade ago. Given that the social workers interviewed for this study perceived these pressures to have intensified over time, we might assume that this figure would not be likely to decrease.

$\mathrm{v} \quad$ The majority of social work case notes and reports are digitised but there can be times when a hard copy is required for court appearances.

vi This informal culture incorporated elements of hegemonic masculinity. We do not have space to expand on this here. However, it is important to acknowledge the gender dimensions in how time is controlled and how this plays out in social work practice. Caring work in particular has a temporal logic - fluid, relational and cyclical - that can be contrasted with the linearity of market capitalism and male-dominated productive work (Bryson 2007).

\section{References}

Adam, B. 1990. Time and social theory. Cambridge: Polity.

Adam, B. 2004. Time. Cambridge: Polity. 
Auyero, J. 2012. Patients of the State: The Politics of Waiting in Argentina. Durham: Duke University Press.

Bastian, M. 2014. Time and community: A scoping study. Time \& Society. 23(2): 137-166.

Bryson, V. 2007. Gender and the Politics of Time. Feminist theory and contemporary debates. Bristol: Policy Press.

Chan, C. 2016. ICT-supported social work interventions with youth: a critical review. Journal of Social Work DOI: 10.1177/1468017316651997.

Colley, H., Henriksson, L., Niemeyer, B., \& Seddon, T. 2012. Competing time orders in human service work: towards a politics of time. Time \& Society. 21(3), 371-394.

Danermark, B., Ekström, M., Jakobsen L., \& Karlsson, J.C. 2002. Explaining Society. London: Routledge.

Davies K. 1994. The tensions between process time and clock time in care-work: The example of day nurseries. Time and Society 3: 277-303.

Dominelli, L. 2009. Positioning social work, in R.Adams, L.Dominelli, M.Payne (eds.) Social Work: Themes, Issues and Critical Debates. London: Palgrave.

Fahlgren, S. 2009. Discourse analysis of a childcare drama: Or the interfaces between paradoxical discourses of time in the context of social work. Time \& Society, 18(2-3), 208-230.

Ferguson, H. 2006. Liquid social work: Welfare interventions as mobile practices. British Journal of Social Work, 38(3), 561-579.

Garrett, P.M. 2005 Social work’s electronic turn: notes on the deployment of information and communication technologies in social work with children and families. Critical Social Policy 25(4): 529-553.

Guest, G., Bunce, A., \& Johnson, L. 2006. How Many Interviews Are Enough?: An Experiment with Data Saturation and Variability. Field Methods, 18 (1):1 59-68. 
Halberstam, J. 2005. In a queer time and place: Transgender bodies, subcultural lives. London: NYU Press.

Harris, J. 2003. The Social Work Business. London: Routledge.

Hassan, R. 2009. Empires of speed: Time and the acceleration of politics and society. Leiden: Brill

Hirvonen, H. \& Husso, M. 2012. Living on a knife’s edge: Temporal conflicts in welfare service work. Time \& Society, 21 (3): 351-370.

Juhila, O., Günther, K. \& Raitakari, S. 2015. Negotiating mental health rehabilitation plans: Joint future talk and clashing time talk in professional client interaction. Time \& Society, 24(1), 5-26.

Marshall. M.N. 1996. Sampling for qualitative research. Family Practice, 13 (6): 522525.

Melucci, A. 1998. Inner time and social time in a world of uncertainty. Time \& Society, 7(2-3), 179-191

Munn, Nancy D. 1992. The cultural anthropology of time: A critical essay. Annual Review of Anthropology, 21(1), 93-123.

Munro, E. (2011) The Munro Review Of Child Protection: Final Report, A ChildCentred System. London: The Stationery Office.

Parton, N. 2008.Changes in the Form of Knowledge in Social Work: From the 'Social' to the 'Informational'? The British Journal of Social Work, 38(2), 253-269

Philip. M. 1979. Notes on the form of knowledge in social work. Sociological Review 27 (1): 83-111.

Pösö, T. \& Eronen, T.. 2015. Five years in care: Documented lives and time trajectories in child welfare. Child \& Family Social Work, 20(2), 202-210. 
Ricouer, P. 1990. Time and Narrative, Volume 1. Chicago: University of Chicagoe Press.

Roberts, L. 2017. Time to change? Exploring the impact of time-limited service provision in a family support service. Child \& Family Social Work 22 (S3)

Rosa H.. 2003. Social Acceleration: Ethical and Political Consequences of a Desynchronized High-Speed Society. Constellations 10: 1: 3-33.

Rosa, H. and Scheuerman, W.E. 2009. Introduction. In: Hartmut Rosa and William E. Scheuerman (eds) High-Speed Society: Social Acceleration, Power and Modernity. Pennsylvania State University Press.

Sharma, S. 2014. In the meantime: Temporality and cultural politics. Duke University Press.

Statham, J., Cameron, C. \& Mooney, A. 2006. The tasks and roles of social workers: a focused overview of research evidence. TCRU, Institute of Education, University of London.

Timmermans, S. \& Tavoy, I. 2012. Theory construction in qualitative research: from grounded theory to abductive analysis. Sociological Theory 30(3): 167-186.

Tomlinson, J. 2007. The culture of speed: The coming of immediacy. London: Sage.

Urry, J. 2000. Sociology beyond Societies: Mobilities for the Twenty-first Century. London: Routledge.

Ylijoki, O. H., \& Mäntylä, H. 2003. Conflicting time perspectives in academic work. Time \& Society. 12(1), 55-78.

Yuill, C. 2017. The use of abduction in alienation research: a rationale and worked example. Social Theory and Health 15(4): 465-481.

Zerubavel, E. 1981. Hidden Rhythms: Schedules and Calendars in Social Life. Chicago, IL: University of Chicago Press. 